\title{
ADVANCES IN SEISMIC RISK MANAGEMENT IN DEVELOPING COUNTRIES
}

\author{
Shirley MATTINGLY ${ }^{1}$
}

\begin{abstract}
SUMMARY
Earthquakes threaten local, national, and regional stability and impede momentum toward sustainability. In the developing world's rapidly growing cities, factors that increase vulnerability are frequently present: burgeoning populations, uncontrolled development spreading into marginal and hazardous areas, and faulty construction practices. Poverty, social and economic marginalization, and inadequate access to education and employment limit the choices of increasing numbers of urban residents. Local and national governments are faced with everyday disasters in the forms of pollution of the air and water, inadequate sanitation, and health care crises, which demand more immediate attention than the more remote possibility of a devastating earthquake striking their city. Seismic risk can expand unchecked in the absence of adequate awareness, commitment, and capacity to address it.

Focused efforts initiated during the latter half of the 1990s, the decade designated the International Decade for Natural Disaster Reduction (IDNDR), are generating a shift from reliance on response and relief to proactive risk management and mitigation programs in some of the cities most at risk from earthquakes. Scientists, engineers, public officials, journalists, community leaders, and the public have been drawn into a team effort. Various international organizations have partnered with these local coalitions in efforts to foster a more comprehensive, holistic approach to risk management and to protect urban residents, infrastructure, and the environment from earthquakes' effects.
\end{abstract}

\section{HAZARDS, HUMANS, AND THE BUILT ENVIRONMENT}

\section{Hazards and the Environment}

Natural hazards help to shape our natural environment--sometimes suddenly, sometimes over geologic time. Natural events "shape the topography, deposit volcanic soils, flush estuaries, water the land, expose buried resources, dispose of combustible material, and continually reset regenerating cycles into motion" [Bender, 1990]. Natural hazards can damage the environment; they kill living things, change the ecosystem, and affect the habitat of endangered plant and animal species. Yet, the impacts of hazard events on the natural environment typically have not been a major topic of focus for environmental studies.

Nevertheless, the linkages between hazards and the environment are increasingly being recognized and have begun to impact current thinking regarding environmental and hazards management. For instance, research by India's Disaster Mitigation Institute (DMI) indicates that mitigating natural disasters and conserving natural resources are directly "and unavoidably" linked. As stated in a paper by DMI Director Mihir R. Bhatt, "It is we who are separating the two - natural disaster mitigation and natural resource conservation - in our top-down and sectoral approaches" [Bhatt, 1999]. 
It is human intervention that complicates the interaction between hazards and the environment. Human interaction with the environment and hazards provides the third point in an interactive triangle. We humans tend to take our environment for granted without great regard for its fragility. Our air, water, food, energy, and building materials are, of course, all part of our ecosystem. There are many possible interactions between the earth's ecosystems and humanity's social and constructed systems. Our interaction with the environment places the environment, and in turn humans, at risk from natural hazards. Human pollution of the air, land and water, and destruction of many of the world's rainforests is changing the world climate. It is human intervention that compounds the impacts of natural hazards events and turns those events into disasters.

It is increasingly being recognized that disaster impacts are the result of the interactions among and within these three interconnected systems and their subsystems:

1. The earth's physical systems (e.g. the atmosphere, biosphere, cryosphere, hydrosphere, and lithosphere)

2. Human systems (e.g. population, culture, technology, society, economics, and politics)

3. Constructed systems (e.g. buildings, roads, bridges, infrastructure, utilities, and housing)

Interactions among these systems are clearly illustrated in the following example: "In 1971 changing international politics increased the economic demands of the Cold War. In earthquake-prone Armenia, steel originally intended to reinforce family housing was used to make weapons instead. This left the structures in the city of Leninakan vulnerable to even moderate ground shaking. At the same time, a high rate of population growth due in part to religious beliefs increased the density of people living in buildings constructed since 1971 . The loss of 25,000 lives in the 1988 Spitak quake thus was the result of interactions among construction practices, international political conditions (the Cold War), culture (religious beliefs), and the lack of economic resources (funds to relieve housing density)." [Mileti, 1999]

Some efforts to mitigate or reduce hazards impacts may threaten or further degrade the environment. For instance, population densities in vulnerable coastal areas in the United States continue to increase. Some of the risk from hurricanes is reduced by improvements in hurricane monitoring and warning systems and improved wind-resistant building construction techniques. But when we build on the shoreline, dunes and other natural features can be damaged, pollution increased, and fragile shoreline areas degraded.

Traditional views toward the environment have exacerbated risk in both developed and developing countries. Water, air and soil used to be viewed as inexhaustible resources. Social values were seen as constant. It was believed that the environment could be managed sectorially, that environmental management was a technical matter, and that technology could make anything possible. However, increased understanding of the interactions among human systems, the built environment, and the natural environment have led to changing views. We now know that water, air and soil are finite resources. All parts of an ecosystem are inter-related. Social values change. Environmental management involves policy, institutions and people. And the use of technology has its limits and costs [Biswas, 1997].

Human activities can deplete, conserve, or augment resources. They can increase or reduce the risk related to natural hazards and the potential impacts of hazard events. In developing countries, the poor, widely recognized as being most at risk from disaster, often use, misuse, and deplete the natural environment around them in their everyday efforts to meet their basic needs. For example, deforestation leads to erosion and mudflows, damaging or destroying crops, homes, businesses and industries, water quality, jobs and lives. The poor typically live in highly vulnerable settings due primarily to the locations for their housing being in marginal, more hazard-prone areas. It has been estimated that in Asia, one-quarter of the urban population lives in slums [Litvin, 1998]. The rural poor migrate to the cities, where they occupy land often unsuitable for housing or other uses--gullies, steep hillsides, river beds, and next door to polluting industrial plants. This is a formula for catastrophe, such as the 1984 disaster in Bhopal, India, when 3,000 people, mostly slum residents, died from a release of industrial toxic gas. 


\section{Sustainable Development and Risk Reduction}

In view of the linkage between poverty and vulnerability to disaster, economic development might be assumed to be an important strategy for reducing vulnerability. Yet, historically, there has been a mixed and often negative relationship between development and vulnerability. Some of the factors that have worked against sustainability in the past include:

-- Rising rates of resource consumption and depletion

-- Environmental destruction from waste products of production

-- Development of new technological, chemical and biological hazards

-- Increased occupancy and use of marginal lands

-- Concentrations of population and technological hazards [adapted from Anderson, 1993]

Development has negatively impacted vulnerability to disasters, and disasters have negatively impacted development. Many investors, both private and public, have believed that money spent on disaster prevention is money taken away from development. Now, however, the emphasis is on sustainable development, or development which meets the needs of the present without compromising the ability of future generations to meet their own needs. Building protective measures into new development, and siting it more wisely, can lead to sustained development and stability. Prevention and protection must be shown to be cost-beneficial if a climate conducive to sustainable development is to be created.

\section{GROWING URBAN RISK}

\section{Cities and Environmental Problems}

The worldwide trend toward greater urbanization is commonly considered as a major factor contributing both to environmental problems and the increase in vulnerability to disaster. The population of the world's cities is expected, in a United Nations estimate, to double to 5 billion inhabitants by the year 2025 [Litvin, 1998]. As cities grow, they become increasingly vulnerable to a number of hazards and failures related to inadequate resources to support their populations and to the production of harmful wastes that cannot be adequately disposed of. There is increased potential for disease and for hazards from accidents including explosions of fuel supplies, leakage or spills of chemical and other toxic substances, air and groundwater pollution, and fire. Also, urban dwellers are also dependent upon networks and systems, such as communications and transportation that can fail.

A 1998 survey of development and the environment by The Economist reported that, in addition to urbanization, population growth and industrialization are also blamed for causing environmental problems. Most of the world's population growth will be in developing countries. Rapid urbanization exacerbates the impacts of population growth. And, in many developing countries, industrialization degrading air quality through factory emissions and automotive exhaust fumes.

Poverty and the lack of capacity of governments and institutions to implement and enforce protection policies also play a large part in contributing to environmental problems. Urban density, especially in informal settlements and slums, leads to overcrowding and increased risk of health problems and disease. There is inadequate funding for providing clean water supplies and proper sewage for all urban dwellers. There are inadequate supplies of clean burning fuels. Corruption can also make an impact. The Economist's Survey makes the point with an anecdote about one area within Bangkok's Klong Toey slum that is relatively free of refuse. In this area, residents pay for a scheme that rewards people with eggs for rubbish they deliver to a collection point. This is reportedly cheaper than bribing official rubbish collectors to do their job [Litvin, 1998].

\section{Challenges Facing Cities}

Today's cities and public officials face enormous challenges in the degradation of the environment and quality of life for residents and the increase in risk from natural and technological hazards. Urban populations grow and 
development spreads into increasingly hazardous areas. Land unsuitable for development becomes home to the urban poor -- perching on unstable slopes, in watershed areas, and in and along riverbeds prone to flooding. Fires, floods, and epidemics can sweep rapidly through informal settlements. Overcrowding, inadequate controls over land use and construction, and careless handling of hazardous substances exacerbate risk from natural and technological hazards. In some cities, residents report that buildings and bridges collapse spontaneously, without an earthquake or other event triggering the failure.

Work often takes me to Bangkok, where air pollution causes inestimable health costs and where traffic congestion rivals the worst in the world. I grew up in Los Angeles, famous for chronic traffic congestion and air pollution, but when I go to Bangkok or Delhi or Mexico City or even Kathmandu, the traffic jams and poor air quality overwhelm me. The World Bank has estimated that air pollution in China caused 178,000 premature deaths among city residents in 1995 and 1.7 million cases of chronic bronchitis [Litvin, 1998], causing high economic costs. And in many cities the water is even more polluted than the air. An estimated 1.2 billion people around the world have no access to clean water, and 2 million children die needlessly every year because their water is contaminated by sewage. The poor, often without access to a safe municipal water supply, turn to vendors who often draw water from polluted rivers or other contaminated sources and charge many times more than the cost for tap water -- in Jakarta 60 times more, in Karachi 83 times more, based on a report by the World Commission on Water for the 21st Century [Kibel, 1999].

In addition, growing cities around the world produce mountains of solid waste, and local governments often cannot even begin to manage, collect and dispose of it properly, in ways that protect both environment and residents.

Almost two years ago in Nepal I met with the Mayor of Kathmandu. He was politely attentive when I spoke of the importance of reducing risk from earthquake, fire, and other hazards in his city. But he said plainly that every day, he faces a solid waste disaster, and until he is successfully handling that disaster, other threats must take a back seat. A walking tour along the river that runs through the city reinforced his compelling argument. Nevertheless, while he is focusing his efforts on solid waste, he is also quietly supporting the efforts of a small Disaster Management Unit, which he established in the city's Social Welfare Department. And the head of the Social Welfare Department has established a new Disaster Management Committee of city department heads, patterned after a model that works well in Los Angeles. And this department head has a strong partner in the National Society for Earthquake Technology-Nepal, or NSET. NSET itself is applying lessons and approaches learned in California, tested in Quito, Ecuador in GeoHazards International's Quito Project, and refined in Kathmandu.

In many developing countries, urban residents are increasingly at risk. In fact, human society--all over the world--continues to place itself at risk, often even when it knows better. Risk seems to grow at a much faster rate than the awareness, commitment, and capacity to deal with it. And many local governments throughout the world are not strong enough to take on leadership in risk management and prevention.

Cities all have unique circumstances and special challenges, but they also share--to some extent--common challenges and difficulties, such as inadequate budgets, inadequate public awareness and concern about hazards and risk, and inadequate political will to make the hard decisions necessary to protect the environment and residents, limit growth in hazardous areas, and enact and enforce strong codes and construction quality control.

\section{Community Attitudes and Practices}

It has been noted that some types of environmental pollution and disasters seem to receive more attention or be more popular than others [Bernstein, undated]. In developing countries there is often more focus on controlling industrial pollution than on building safe and hygienic systems for disposing of human wastes in poor neighborhoods. Industrial pollution may be more easily managed, as the problem may be confined to an industrial site. Industrial pollution problems are often more interesting to the media, and more press coverage will come from fighting a large multi-national corporation than from building sewers in poor neighborhoods.

The fact is, however, that everyday local practices, such as dumping waste oil on the ground or household waste in the river, lead to environmental degradation. Many of these activities and practices that negatively impact the urban environment are beyond the control of the government. Environmental agencies are usually not equipped to change attitudes and common practices. 
Public attitudes affect local practices and official policies. It is hard for a government to spend scarce resources on problems that are not perceived as negatively impacting citizens' normal lives. It takes a great deal of effort to mobilize public opinion and change habits and customs. It usually takes a triggering event, such as a catastrophe, to cause even temporary changes. Ideas must be "sold" to the people whose changed practices can reduce environmental degradation. For that matter, it has been noted that "Without a large measure of voluntary compliance there is not much point in establishing government policies to deal with environmental degradation and natural disaster mitigation: enforcement of new regulations will be neither thorough nor cost-effective" [Bernstein, undated].

However, if a community is mobilized, it can make an impact in environmental protection. One example of popular mobilization is the Chipko Andolan in India, which has protected trees from logging by embracing them.

What can be done to provide environmentally sustainable, healthy and liveable human settlements? The Global Plan of Action: Strategies for Implementation (see website www.hsd.ait.ac.th) includes a six-page list of actions that governments and interested parties can take under this single initiative alone. The suggested implementation strategies include such steps as strengthening environmental health services, promoting safe and healthy workplace conditions and housing, setting and monitoring environmental standards, undertaking environmental assessments for development projects, managing use of toxic substances and disposal of waste, providing clean water, organizing recycling, managing water resources, and involving the community in program development and implementation.

These actions presume the existence within government, other institutions, and communities of the capacity to undertake these kinds of actions. This presumption may not be realistic. Developing or improving the institutional capacity of government, professional groups, and other organizations to address environmental problems and hazards is a necessary immediate step.

\section{RISK MANAGEMENT AS A FACTOR IN URBAN GOVERNANCE}

\section{Building Capacity for Risk Management}

Risk managers, environmental managers, and land use planners all possess techniques and methodologies for assessing and analyzing impacts of human activities on the environment, and impacts of nature's hazards on human activities. We have the tools and strategies for protecting the natural environment and protecting people. The challenge lies in integrating our efforts and applying the tools and strategies available to us. In bringing together environmental interests and hazard reduction interests to work together. In building public awareness and political will, and translating public awareness and political will into action.

We know, in large part, how to assess hazards and vulnerability, set goals, and write a land use plan or risk reduction plan. The hard part is turning the plan into action, and this requires building local capacity to undertake risk reduction and environmental protection actions.

This capacity building effort is needed to enable governmental officials and staff to develop the necessary skills, knowledge, and attitudes to effectively partner with other players in hazard reduction and land use management. Government employees, the private sector, and the public should be educated about environmental degradation and mitigation measures as well as hazards, vulnerability, and risk reduction measures. Greater awareness of existing conditions, assessment of the impacts of human activities and development on those conditions, and involvement of stakeholders in consensus decisions are factors that can help lead to more sustainable land use.

\section{Institutional Capacity for Managing Land Use}

We can apply land use solutions to hazards problems, although the reality is that these actions are not easily taken. Basic tools for land use management include: regulating land use and development, proper siting of public infrastructure and critical facilities, property acquisition, taxation and fiscal policies, and information dissemination/education of potential investors, developers and occupants. The best mix of use of these tools depends on the community and the circumstances, the culture and political will and economic reality and a host of factors. 
Regulating and controlling land use presents one of the most effective tools to mitigate disaster impacts in the long term, but it is also one of the most challenging to implement systematically and effectively. Political will is the first prerequisite for controlling land use. Political leaders at each level of government must be willing (or must be convinced) to take action to protect the future of their cities and inhabitants by insisting that land use be surveyed and monitored and by developing, enacting and enforcing land use management programs and regulations.

One of the first problems is separating and defining the roles of different levels of government. Often there are competing or conflicting interests among national, provincial or state, municipal and other local level authorities. In some countries separate urban development authorities have been established apart from municipal or other levels of government in order to provide a more independent and longer range view in regard to land use.

Organizational capacity for implementing and enforcing land use regulations should be developed within government at each level. Planning agencies should have oversight over spatial and physical planning, project identification and development programming, and financing mechanisms. They should also have a direct role and responsibility in disaster mitigation and management, so that programs are integrated, i.e., so that mitigation of potential disaster effects is an integral objective in land use management programs. Integration of disaster mitigation and land use management objectives can help to ensure that risk reduction is one criterion taken into account in evaluating development and building proposals, that building regulations are amended when new hazard risk information is developed, and that new critical facilities (those important to disaster response and recovery) are sited in more accessible, safer areas.

A recent assessment of the current state of knowledge about urban planning and land use management in the United States indicated that the basic elements of technology to manage development were in place by the early 1970s but they were little used. Researchers then focused on what factors encourage local governments to adopt development management techniques, and they identified the following [Burby, 1997]:

-- Federal or state mandates require attention to mitigation of hazards in urban comprehensive plans

-- Federal or state governments provide measures to encourage compliance with the mandates, through incentives or sanctions and grants or technical assistance to help build capacity

-- Citizens and interest groups recognize hazards and want something done to reduce risks

-- The problem has been "catalyzed" by a hazard event or rapid development of particularly hazardous areas

-- The problem can be addressed through adjustments in land use and building techniques

-- Comprehensive plans recommend the adoption of such measures

-- There is commitment and capacity on the part of planning and code enforcement leadership and staff to do something

-- The city has the tax base to generate resources to support development management measures

Typically, local governments are much more willing to take action to regulate land use in regard to future development rather than in regard to areas that have already been developed. They also have been found to be more apt to adopt measures that increase disaster resistance of buildings than to affect the location of buildings.

Research by Burby and others also indicates that private sector compliance with land use planning regulatory mandates is less than complete. And little is known about to what extent recent advances in hazard assessment technologies and their increasing use are actually affecting community planning and actual development decisions. In view of the insufficiency of legal mandates to change practice, it is recognized that change must grow out of leadership, public and private, and involvement of citizens, community groups, and professional organizations. 


\section{Overcoming Obstacles}

The primary barriers to development and enforcement of strong mitigation practices including land use management are inadequate political will, inadequate institutional capacity, and inadequate legal framework establishing clear authorities and responsibilities and penalties for non-compliance. Other obstacles include the political influence of landowners and developers, societal disregard for government policies and regulations, governmental disregard for policies and regulations established by other governmental levels or agencies, graft and corruption, economic factors, and a perceived (or real) lack of viable alternatives.

One method of overcoming some of the obstacles involves offering development incentives and disincentives to the private sector to encourage mitigation practices and proper land use. Possible incentives might include:

-- Offer land development subsidies in some areas and levy development overhead charges in others

-- Encourage the location of industries and neighborhoods in safe areas by giving those areas priority for installation of utilities and urban services

-- Encourage the use of certain areas through differential land pricing (in the case of undeveloped or underdeveloped land) or by subsidizing transportation from those areas to areas of employment, stores and businesses

-- Inform the public about hazards and land use as a mitigation tool, so that they will consider the risks they may face if they move to particular locations.

\section{Community Participation}

Community involvement in development planning decisions should come early in a project, when it is still in the initial feasibility study stage. The success of a project can depend partially on maintaining local understanding, goodwill, and support. For instance, if local drainage channels are constructed without local participation and understanding, they may soon become useless and unable to perform their function in a flooding situation if local households have been using them to dispose of solid waste materials.

Once a city or community has set its hazard reduction goals, policies and priorities, it should bring it all together in an action plan. This might be a stand-alone plan or a hazard reduction element of a general plan. The action plan will lay out the priorities of the community and strategies and actions to achieve them. Responsible agencies, potential funding sources, and timetables should be identified for each action. The actions may include enacting or strengthening code provisions or enforcement or other initiatives that will reduce hazards impacts, including governmental projects to build or reinforce roads, bridges, utilities, dikes, levees, and retaining structures.

\section{LEGAL, POLICY, AND INSTITUTIONAL FRAMEWORKS FOR SEISMIC RISK MANAGEMENT}

Through work in many different cities and countries, it is clear to me that one of the most vexing obstacles to effective risk management is the lack of a strong legal and institutional framework--sometimes at the national level, typically at the city level, and often at both levels.

In some countries, authorities and responsibilities for mitigation and disaster management are unclear, unstated, or ignored. Institutional arrangements may be lacking. In other countries, while authorities and systems for disaster response and relief are well established, this is not the case for mitigation. As local risk reduction efforts emerge, they generate demand for national attention to--and funding for--mitigation.

Barriers to institutionalization are well recognized. For instance, in some countries, the currently evolving balance of power among national, provincial, and municipal level authorities must be sorted out. The legal framework for risk management may be inadequate, and government may lack the organizational capacity for implementing mitigation strategies and building capability for emergency response and disaster recovery. In fact, facing these obstacles, in one city in Indonesia they have adopted a strategy of "Ready, Fire, Aim", or, essentially, act first and plan later. Time is short, so we just fire, trying to hit the target while aiming. Action is better than paralysis. 
In both the IDNDR's RADIUS Program and the Asian Disaster Preparedness Center (ADPC)'s Asian Urban Disaster Mitigation Program (AUDMP), a natural focus of attention has been the legal and policy frameworks and institutional arrangements. Project partners have grappled with how to get the scientific and technical information produced through the Projects disseminated and applied. Legal and institutional issues, barriers and deficiencies have become apparent as Project partners complete hazard and risk assessments and face the challenge of trying to institutionalize mitigation and disaster management practices, and to "operationalize" existing stated but often disregarded mitigation-related policies. In a 1999 workshop for sharing experiences among the AUDMP projects in various countries, it was evident that deficiencies in legal and institutional frameworks are presenting obstacles to local efforts to institutionalize mitigation. ADPC, however, is assisting the project teams to identify these issues and work with stakeholders at the local and national levels to develop locally-based and consensus-based approaches to these issues.

In Colombia, following the January 25, 1999 earthquake that struck Armenia, Pereira, and other towns in the country's coffee-growing zone, serious policy and institutional framework issues related to earthquake recovery were immediately apparent to some local people. The subdirector of the municipal planning office in Pereira told us that the earthquake "affected the city physically, socially, economically, and has changed the dynamics of everyone's responsibilities... There is a need to restructure the processes and the responsibilities of the players involved." Local interests should drive the recovery and reconstruction process, he believed, adding "We do not want the central government, or anyone else, to come in without respecting our existing processes and our ideas" [GeoHazards International Reconnaissance Team, 1999].

One example of a framework that has proven successful in a developed country is serving as a basis for discussion about framework enhancements in several other cities and countries. The legal and institutional framework developed in Los Angeles for risk management and prevention was born 20 years ago, the result of political interest sparked by local and international disasters. The model is grounded in a strong legal framework that assigns responsibilities to various organizations. A full-time risk management staff operation under the direction of the Mayor is supported by line operations carrying out clearly delineated authorities and responsibilities for specific aspects of risk management and prevention, such as structural design and construction control (the Building and Safety Department), environmental protection (the Environmental Affairs Department), and land use management (the City Planning Department). Making alliances with planning and development agencies is proving an especially critical factor in the cities in developing countries that are replicating this kind of interinstitutional approach. The Los Angeles strategy involves other levels of government, non-governmental organizations, groups of citizen volunteers, and an alliance with the local business community. The Los Angeles legal and institutional framework and collaborative approach has functioned well for 19 years, regardless of politics and changes in administration.

\section{ADVANCES IN ASSESSING AND UNDERSTANDING RISK}

Collaborative approaches to assessing, understanding, and reducing risk are increasingly producing positive results in a number of cities with seismic risk. These successes are being shared with other cities through a variety of mechanisms including IDNDR generated projects and workshops, and the increasing ease of communication through the internet.

\section{The Quito Project}

The Quito Project was a groundbreaking collaborative international project, initiated in 1992 that brought together a multidisciplinary local team in Ecuador with a multidisciplinary international team to address seismic risk in Ecuador's capital city. The project was conceived and organized by a California scientist, assisted locally by a French geotechnical firm, and backed financially by a Japanese corporation.

Jeannette Fernandez, Professor of Engineering at Quito's Escuela Politecnica Nacional and a key project participant, wrote about her experience in the following words: "In working with GHI on Quito's earthquake risk, I learned that engineers and scientists must work with the community's politicians, emergency response personnel, and businessmen" [Fernandez, 1997]. Professor Fernandez currently shares Quito's experience in understanding and addressing seismic problems through continued participation with GeoHazards International (GHI), a non-profit organization based in California. 
Ecuador's President, Jamil Mahuad, Mayor of Quito at the time of the project, has noted the importance of sensitivity to political matters in addressing seismic risk, stating: "I want to thank GHI for conducting this project with the greatest respect for the needs of Quito, and for the sensitivity with which you handled political matters related to earthquake safety plans" [GeoHazards International, 1999].

These quotations provide clues to some of the successes of the Quito Project: effective partnerships, sensitivity to local institutions, and engaging the entire community in developing a consensus-driven process and action plans. A paper by Professor Fernandez and collaborator Hugo Yepes provides insight into several of the strategies considered useful in achieving good results [Fernandez, 1997]:

-- Working in multi-disciplinary teams

-- Building partnerships among different countries and institutions, and

-- Trying to find locally specific solutions

Professor Fernandez also astutely identified the key to sustainability: "A lot of work has to be done directly with the lay community, trying to look for long term solutions through developing capacity and awareness in different target groups, especially low income groups in the city. This will bring in the long run not only vulnerability reduction, but also sustainable development. So, the capacity and desire of the local community to reduce their own vulnerabilities is the keystone for building sustainable solutions" [Fernandez, 1997].

\section{The Bogota Multidisciplinary Risk Mitigation Project}

In the neighboring capital city of Santa Fe de Bogota, Colombia, an ongoing partnership between the Universidad de los Andes, the National Institute of Geosciences, and national and municipal governments has produced hazard and urban seismic risk assessments for Bogota. After obtaining data related to soil amplification using soil dynamic lab studies and analyzing strong-motion records of recent earthquakes, loss estimations were prepared for different types of buildings and lifelines systems. The loss estimations have been used in design of emergency response plans, for public information, and for education activities. They also have led to the study of new requirements for urban planning, more detailed vulnerability studies of utility networks, seismic provisions in building codes, and reinforcement of key buildings.

The Bogota project has proceeded through a three-step process:

1. Evaluation of the seismic hazard and microzonation of the city

2. Estimation of earthquake loss scenarios

3. Formulation and application of mitigation measures for seismic risk.

In Colombia, the destruction of the town of Armero caused by the 1985 eruption of the El Ruiz volcano resulted in national legislation establishing national and local level systems for disaster management, including establishing a requirement for Interinstitutional Committees for Risk Mitigation and Disaster Preparedness, headed by the elected governor or mayor. These committees are now the focus of efforts in risk reduction, prevention, and emergency response in a growing number of areas of the country. The January 25, 1999 earthquake that struck Armenia, Pereira, and other towns in the coffee-growing zone of the country, further focused attention on the need for mitigation and preparedness actions throughout the country. In $\mathrm{Santa} F e$ de Bogota, a number of significant mitigation actions have been or are being carried out, including:

-- Updating seismic code standards

-- Evaluation of seismic vulnerability of hospitals and design of their rehabilitation and structural and non-structural reinforcement

-- Detailed evaluation of vulnerability of critical points of lifelines and emergency response plans

-- Development of standards for design of urban gas networks. 
In the words of Omar Dario Cardona of the Universidad de los Andes, "this project is an example of a study in a developing area, where the political will and the agreement of the different institutions involved, constitutes the basis to get effective results; without a huge amount of financial resources as is usually required" [Cardona, 1999].

\section{FOCUS ON RISK REDUCTION}

\section{Changing the Paradigm}

Working in Latin America and Asia, I have seen successful local efforts to change the hazards paradigm, from one of largely ignoring the threat until the event occurs, to one of anticipating and reducing disaster impacts. In Sri Lanka, for instance, the majority of land use planners in the country's Urban Development Authority were recently trained in risk assessment and risk management techniques. In Sri Lanka's capital city of Colombo, in the wake of flooding last April, the Municipal Council created a multi-agency Crisis Management Committee to organize prevention measures. Mitigation action planning, introduced through international training, is taking hold as a real community effort in several Sri Lankan cities.

In the municipality of Ratnapura, the gem mining capital of Sri Lanka, new partnerships resulted in development of a new land use map and plan that take hazard reduction into account. The local officials teamed up with land use planners and scientific and technical organizations to create maps that better display hazards and risk, enabling the development of better plans and practices, and ultimately protecting development from hazards. The city has also created a multi-disciplinary Disaster Management Steering Committee to address disaster prevention and mitigation in a coordinated approach, involving the community. In Ratnapura, their projected outcome is not just a better land use and development plan (not a small feat!), or increased public awareness of risk and risk reduction, but also "good governance," which is something everyone can aspire to.

In Naga City in the Philippines, concerted efforts by inspired local officials are shifting the focus of the city's economic activities to less vulnerable locations. They are successful because they have implemented a model of strong community involvement and a strong association with overall development programming. In San Carlos, also in the Philippines, the local government is now "implementing mitigation without thinking about it," for example, by adding fire hydrants to a water supply improvement project. Increasingly, a culture of disaster reduction is being incorporated into urban development and the setting of community priorities. In some ways, it can be said that Ratnapura and Naga City and San Carlos are doing a better job than some of the cities and approaches they started out to emulate.

\section{The RADIUS Initiative}

RADIUS (an acronym for Risk Assessment Tools for Diagnosis of Urban Areas against Seismic Disaster) is a United Nations sponsored initiative for the International Decade for Natural Disaster Reduction (IDNDR). It was created by the IDNDR Secretariat to focus on the methodology for seismic risk assessment of urban areas in its nine case study cities. The objective was to produce practical tools for seismic risk assessment, based on the experiences in the case study cities. The tools, scheduled for release in October 1999, include [Okazaki, 1997]:

-- A manual to prepare earthquake damage scenarios for urban areas

-- A graphic software for computer simulation as easier application of the manual

-- Case studies

-- A guide for simple assessment of buildings and houses, and

-- Documentary films.

The RADIUS projects in the case study cities were designed around a core partnership between local government and local academic or scientific institutions. They required the mayor's endorsement for a city to participate. The projects worked through a process of assessing the hazard and risk, seeking local input and consensus on the resulting scenarios, then through local collaboration, developing a local action plan to address 
the threat. Addressing implementation issues and sustaining momentum are ongoing challenges for the case study cities extending beyond the program period.

\section{The Earthquakes and Megacities Initiative (EMI)}

This kind of partnering and collaboration between local government and scientific and academic institutions is serving as the backbone of another international collaborative initiative which is determined to assist in implementing risk reduction in cities at risk. The Earthquakes and Megacities Initiative (EMI) focuses its efforts on large cities in the developing world with significant seismic hazard.

EMI is an international scientific non-governmental organization dedicated to the acceleration of earthquake preparedness, mitigation and recovery of large urban areas. EMI grew out of a 1997 workshop in Germany organized by the International Lithosphere Program (ILP) and the World Seismic Safety Initiative (WSSI) to assess the state of knowledge in urban earthquake vulnerability reduction. The organization was created out of sheer will power and dedication of an international group of enthusiasts who were determined to make a difference in megacities at risk.

EMI is acting as a catalyst for the delivery of scientific and technical knowledge to end users with focus on developing capacity in megacities of the developing world, because it is there that the effects of earthquakes can be especially devastating to the people, their economy, culture, and environment. The initial projects in EMI's action plan are a Twin Cities Project to facilitate knowledge sharing and building local capacity, and the organization of a Second International Workshop on Earthquakes and Megacities, held in Manila in late 1999. Twin Cities applies two models used historically in Los Angeles: a collaborative partnership between the City and a consortium of universities tied together as the Southern California Earthquake Center (SCEC), and an early 1990's memorandum of agreement between Los Angeles and Mexico City for emergency preparedness. EMI has arrived just in time, as the IDNDR comes to a close but urban risk continues to grow.

\section{BUILDING DISASTER RESILIENCE}

\section{Disaster Resilient and Sustainable Cities}

There is a vision that has begun spreading from city to city around the world. It incorporates land use planning, environmental protection, and hazard mitigation into what is being described as disaster resistant, disaster resilient, or sustainable cities. These are cities or communities in which hazards are taken into account and development is designed and executed in ways that sustain the natural environment. Characteristics of these communities would include protection from natural and technological hazards, efficient use of land, incorporation of parks and trees and open space, encouragement of pedestrian rather than vehicular traffic, use of renewable energy, and management and reduction of pollution and waste.

This vision has its roots in a paradigm shift that reflects the views of hazards researchers and practitioners alike who are weary of growing risk and losses that are preventable or avoidable. In the United States' assessment of hazards and hazards policy, this shift has been defined as a shift to a new policy of sustainable hazard mitigation that links hazard mitigation with natural resource management and economic and social resiliency. The assessment identified the need for fostering local sustainability. The new focus on local assessment of the hazards, evaluation of the risk, setting of risk reduction goals, and taking action, is seen as the most promising strategy to achieve loss reduction [Mileti, 1999]. These same principles also apply to a large degree in many developing countries.

\section{Involving the community to build "disaster resistant" communities}

In the past decade, governmental and non-governmental organizations in the U.S., New Zealand, and several other countries have begun focusing more attention on incorporating local community interests into risk management and disaster loss reduction agendas. In order to create an informed and involved public that demands reduction of their vulnerability to hazards, we must create opportunities for the public's personal involvement in local preparedness activities and loss reduction decisions. Through personal involvement, members of a community can come to recognize that prevention is in their own self-interest. 
In the U.S., this community-based approach to disaster loss reduction is known as building "disaster resistant communities." This approach strives to generate new and sustainable public-private alliances in an atmosphere of mutual benefit. National and local media are involved, providing publicity and helping to build public awareness and support. Regional and national organizations provide technical assistance, training and supplies, and in some cases the federal government provides "seed money" matched by local businesses. The theme is for communities to become, through their own efforts, more resistant to disaster and more resilient, better able to manage recovery and reconstruction, after a disaster has occurred.

Experience has shown that risk management and prevention need to become an integral part of everyday life. If residents and businesses in a community place low value and low priority on protection and prevention, it is likely their governmental leaders and elected officials will, too.

\section{Partnering with the media}

The media play a critically important role in communicating risk, raising awareness of local and distant disasters, and disseminating information about how to reduce disaster risk. Having an active, ongoing dialogue with local media representatives helps ensure that they accurately portray hazard and risk information. And they can provide tremendous assistance in disseminating appropriate information in the moments, hours and days after an earthquake strikes. A strong partnership with local media should include constant dialogue and collaboration on public awareness campaigns and events.

The Kathmandu Valley Earthquake Risk Mitigation Project in Nepal adopted this very beneficial strategy in heavily involving a local journalist in all aspects of their efforts. The National Society for Earthquake Technology (NSET), the organization that manages the project in Nepal, called upon an experienced reporter to interview operators of critical facilities in order to learn what they knew about the vulnerability of their facilities and systems and the level of organizational preparedness to deal with major emergencies. This proved to be a valuable learning experience for the journalist, plus it placed earthquake awareness and understanding in the hands and mind of someone well-placed to influence the public, someone with a voice that would be and is being heard.

The journalist's first newspaper article on the Kathmandu Valley earthquake scenario resulted in a three week dialogue with children on the streets. He approached the national news agency with an offer to talk with the media about earthquakes, and now, due to high demand, he conducts popular training courses in "disaster journalism." He helped NSET to create a highly successful Earthquake Safety Day, with booths and exhibits, first aid and shake table demonstrations, and hospital and school drills. The safety day has now been institutionalized and included on the official government calendar.

\section{Collaboration between Government and Academic Institutions}

It has become increasingly clear that local governments need to team up with local scientific and technical organizations and universities if they are to understand and effectively address their seismic risk. This has been the case in the examples of Quito and Bogota, cited earlier. In Los Angeles, ongoing partnerships exist between the City of Los Angeles and local academic institutions such as the California Institute of Technology (CalTech) and professional engineering (and other) organizations, such as the Structural Engineers' Association of California. These partnerships are long-standing; in the 1980s Los Angeles teamed up with scientific organizations to develop and utilize earthquake damage scenarios as tools for planning, training, and public policy decision-making.

In the 1990s, a collaborative partnership was established between the City of Los Angeles and a new consortium of universities, known collectively as the Southern California Earthquake Center, or SCEC, working together to unite science, engineering, and public policy. SCEC's scientists represent all the disciplines in the earth sciences. Before SCEC brought them together, many of the scientists did not talk much to each other, let alone talk to engineers and bureaucrats. But in the Center they have united around a common goal of coordinating research on the area's earthquake hazards and applying earth science to earthquake hazard reduction. The Center scientists work with the Outreach Director to help impact public policy by improving the knowledge base of decision-makers, building and design professionals, educators, media reporters and writers, and the public [Andrews, 1998]. The Center's partnerships with the community serves as a model for collaborative efforts in other cities. 


\section{Involve the private sector in meaningful ways}

Private enterprises should be a big player in reducing risk, as it is in their self-interest, but in too many communities there is little or no action on their part. Rather, many industries and businesses increase disaster risk as well as degrade the urban environment through their everyday practices.

A successful model seems to lie, again, in building sustainable partnerships within communities, in this case between government and the private sector, a task much more difficult in practice than it sounds, indeed, an endeavor that most U.S. communities are just now tackling through the federal government-supported Project Impact. Los Angeles, however, led the way over 15 years ago in initiating a public-private partnership called BICEPP, the Business and Industry Council for Emergency Planning and Preparedness.

In 1983, the Mayor of Los Angeles and chief executive officer of a major corporation joined to invite executives of other businesses to come together in united efforts to prepare for potential disaster impacts. A voluntary organization was formed, with companies contributing staff time and effort to provide a forum for exchange of information to enhance emergency preparedness and contingency planning within the Los Angeles business community. BICEPP evolved into a non-profit corporation that provides opportunities for networking and learning how to be more self-reliant. It is still going strong in Los Angeles and the idea has been adopted in several other cities. Most recently, BICEPP served as the inspiration for, and is now a sister organization to, Japan's Crisis Management and Preparedness Organization, or CMPO, organized in 1997 [Lee, 1998].

\section{Lessons from Maharashtra}

The pursuit of disaster resistance is catching on in hazard-prone cities around the world. In the state of Maharashtra, India, a broad coalition of people from the community, universities, and the government have been working together to turn their cities and communities from potential future earthquake victims to disasterresistant communities. They have developed a mitigation strategy called Partnerships for Building Safer Communities. This is part of a major effort, supported by the World Bank, which has focused on building risk management capacity as an integral part of recovery and reconstruction from a devastating earthquake in 1993.

The experience of the State of Maharashtra reinforces lessons learned from various other earthquake experiences around the world. Mr. Krishna Vatsa noted some of these lessons in a paper prepared for a 1999 workshop sponsored by ADPC [Vatsa, 1999]:

"[The Plan] showed how synergy, shared goals and vision among different stakeholders could produce outstanding results in a limited time frame."

"The importance of preparation and groundwork, an organized effort within the government to develop commitment for the project, and the value of strong professional capacity should also be noted."

"Experience has shown that in order to get and keep risk reduction on the public policy agenda as an issue of importance to a city, it is important to team up, pool resources, and be persistent. Scientists, engineers, local officials, administrators, managers in private firms and voluntary organizations, educators, the media, and the public all share responsibility for making risk reduction happen in their city."

Additional lessons from Maharashtra include: the importance of preparation and groundwork, an organized effort within the government to develop commitment for the project, and the value of developing strong professional capacity.

\section{INSTITUTIONALIZATION}

\section{Toward An Integrated View of Risk Management}

Population growth, urbanization, and industrialization have created an explosion in construction in the world's growing cities to provide housing, infrastructure and services. The Asian Development Bank has estimated that over the next 25 years, nearly US\$7 trillion will have to be invested in infrastructure in southeast Asia alone, 
mainly in its cities [Yap, 1997]. This massive growth in the built environment translates into more investment and more population at risk from earthquakes in the world's seismic zones, unless development and construction are regulated, monitored and controlled to reduce risk.

Vulnerability reduction measures can be--but are not always--costly, making some investors unwilling to pay an added amount to build in resistance to an uncertain, future event. It requires a conscious decision to invest in reducing potential losses, especially when the day-to-day needs of a city or country or corporation exceed the available resources. Building awareness and understanding of the risk, and appreciation of the costs and benefits of protection measures, however, allows decision-makers to understand vulnerability and decide on mitigation, prevention, and preparedness actions to take before the potential for damage turns into actual damage [Anderson, 1993].

International funding agencies and multinational corporations are often partners in local and national-level investment decision-making in both pre- and post-earthquake environments, and they have a role to play in institutionalizing risk reduction. For instance, at the World Bank, the Disaster Management Facility (DMF) is aggressively pursuing multiple strategies to ensure that disaster prevention and mitigation are integral parts of development. The DMF is promoting the inclusion of risk analysis in Bank operations, improvement in the management of disaster risk in member countries, and development of market incentives for mitigation investments. These and other initiatives can help lead to a growing "culture of prevention" rather than relief and reconstruction. This complements the approaches promoted by several national and international programs previously cited. The philosophy is that natural hazard events occur, and when they occur, people come together and pull together to recover. Instead, let us engage--before disaster strikes--that cooperative spirit and money that would have been spent on relief, and invest in becoming more disaster resistant. Let us integrate seismic protection into the other decisions we make.

It is increasingly clear that in order to avoid the escalation of risk, risk management and prevention need to be integrated into community values and taken into account in everyday decisions. Several steps to achieve an integrated approach to risk management were recommended at a 1999 IDNDR conference in Paris: (1) that [disaster] prevention measures be combined with land use planning and development measures for sustainable management of human settlements and environments; (2) that natural risk prevention policies be harmoniously integrated into a continuum of responsibility among national, regional and local levels; (3) that, in order to complement humanitarian actions and emergency assistance, prevention programs should be set up jointly with sustainable development assistance programs; and (4) that, regarding reconstruction assistance from the international community or insurance, relevant communities and donors be encouraged to embark on reconstruction from the standpoint of prevention; and (5) partnerships with economic interests, especially insurance firms, should be developed [Paris Declaration, 1999].

\section{Integration with Other Community Goals and Objectives}

In developing countries, institutionalizing risk management and prevention is a special challenge. The programs and partnerships we develop must be stronger than the comings and goings of international experts or international funding, or the political fortunes of local elected leaders. We need to think in terms of selling disaster reduction as a package with other social and economic objectives important to a community. We must integrate it into a common agenda in ways that make sense in the local reality, and make risk management and prevention an issue that is easier to "own". We must make it something real people care about, realizing that they have many more pressing concerns.

Everyone in a city is a stakeholder in risk management and prevention, but many people are not aware of the risk or do not regard it as important to their lives. A RADIUS Project Workshop in Antofagasta, Chile, sparked the interest of a broad spectrum of people in reducing earthquake risk in their community. One of the most enthusiastic participants in the workshop was a representative of the local museum. Other participants represented such diverse institutions as the civil registry, insurance agencies, the port, and the minister of a church-in other words, people who are in touch with many other people in the community, people who have the ability to influence many others. They represent terrific potential advocates for risk reduction in general and implementation of the city's consensus priority mitigation projects in particular [Mattingly, 1999].

\section{Establish Sustainable Local Partnerships and Mechanisms for Implementation}

Working with cities both in the United States and in developing countries, I have seen the importance of building coalitions and partnerships internal to the city at risk. Local multi-disciplinary teams and community advisory 
groups should be created to bring together people from diverse backgrounds in collaborative efforts to develop common goals and objectives and to introduce change in the community. A geologist at a premier technical university in Indonesia told me that within his own institution, he never talked with a person in the civil engineering department until they were brought together by a collaborative international program, the Asian Urban Disaster Mitigation Program. This Asian Disaster Preparedness Center (ADPC) program is bringing together technical knowledge in scientific and engineering fields and is having an impact on public policy in a number of Asian cities.

Scientists, engineers, local officials, administrators, and managers in private and voluntary organizations all share responsibility for making risk reduction happen in their community. Scientists and engineers, for example, can collaborate in assisting business people to understand technical information regarding hazards, risk, the response of structures, and design options. Representatives of the insurance industry, local financial institutions, and international organizations and lenders are other members of the community who should be involved, as they can be a source for incentives and play a role in controlling losses. After a disaster, they are major players in financing repairs and reconstruction.

\section{Changing Public Policy and Public and Private Practice}

To a large extent we know what to do to minimize risk and reduce potential disaster losses. Much attention has been focused on solving risk management and prevention problems through structural (engineering) methods, land use and technical approaches. Over the past decade, there have been rapid technological advances allowing us to build structures that are more resistant to earthquakes, wind, and floods, to strengthen existing buildings and to harden critical lifelines against hazard effects.

Also, we have learned much about the social and economic aspects of disaster impacts, and what factors strengthen response and recovery capabilities. We have learned that disaster management and mitigation programs must meet certain criteria for success. For instance, they must:

-- Address real problems

-- Meet the needs of the users

-- Recognize and be adaptable to the environment in which they will be introduced, and

--Provide solutions that are implementable and sound--technically, economically, socially, and environmentally

We have learned that effective risk management and prevention depends largely on networks of individuals and organizations united by a common goal of protecting lives, livelihoods, investments, and the environment.

For technology to be integrated into practice, there must be dialogue between producers and users in multidisciplinary groups. Over this past decade, the multi-sectoral, inter-disciplinary approach to dealing with society's issues, including environmental and hazards issues, has advanced significantly, providing a model that can lead to better and better-utilized outcomes.

The real challenge now in risk management and mitigation is changing policies, practices, and priorities, and acting on available knowledge and mitigation approaches. One theme of the IDNDR was to bridge gaps between science and engineering, and between science and engineering on the one hand and the public and public officials on the other. We have learned that achieving practical application of knowledge, be it about science, engineering, or good public policy, requires constant and concerted effort and multidisciplinary collaboration, learning to speak someone else's language, in a sense, and openly sharing information.

\section{REFERENCES}

Anderson, Mary B. (1993), (adapted by the author from Dr. Anderson's) Draft paper titled "Disaster Vulnerability and Sustainable Development: A General Framework for Assessing Vulnerability." 
Andrews, Jill (1998), "Encouraging Application of Earthquake Research Results," Southern California Earthquake Center Quarterly Newsletter, Volume 4, Number 2, 1998, pp 30-32.

Bender, Stephen O. (1990), "Environment and Disasters: Tying Natural Disaster Prevention to Development Contributions and Constraints for International Development Assistance," Colloquium on the Environment and Natural Disaster Management, June 27-8, 1990, Washington, D.C.

Bernstein, Janis D. (undated), "Managing Hazard-Prone Lands in Cities of the Developing World," The World Bank.

Bhatt, Mihir R. (1999), "Integrating Natural Disaster Mitigation with Natural Resource Conservation," IDM Paper, March 16, 1999.

Biswas, Kalyan (1997), Adaptation by the author of lecture materials prepared and presented by Mr. Biswas at the Urban Disaster Mitigation course, Asian Disaster Preparedness Center, October 1997, Bangkok, Thailand.

Burby, Raymond J. (1997), "Organization of Mega-Cities: The Planning and Decision-Making Perspective," First International Earthquakes and Megacities Workshop, September 1-4, 1997, Seeheim, Germany, Release II, The United Nations University, pp 309-318.

Cardona, Omar Dario (1999), "Multidisciplinary Risk Mitigation Project of Bogota, Colombia," Paper prepared for Earthquakes and Megacities Initiative (EMI) Twin Cities Meeting, Seeheim, Germany, March 14-16, 1999.

Fernandez, Jeannette, and Hugo Yepes (1997), "Knowledge and Technology Transfer: Improving the Urban Seismic Risk Management in Quito-Ecuador," First International Earthquakes and Megacities Workshop, Seeheim, Germany, Release II, The United Nations University, pp 295-300.

GeoHazards International Reconnaissance Team (1999), "Effects of the January 25, 1999 Colombian Earthquake As Viewed by Authorities in Pereira, Colombia."

Kibel, Amanada and The Associated Press (1999), "World's poor pay most for drinking water, commission says," CNN Interactive, August 6, 1999.

Lee, Robert G. and Nathan L. Rhoden (1998), "CMPO - The BICEPP of Japan," BICEPP Bulletin, Fall 1998, p 1 .

Litvin, Daniel (1998), "A Survey of Development and the Environment," The Economist, March 21st, 1998, p 9.

Mattingly, Shirley (1999), "Risk Management and Prevention in Big Cities: Adapting Successful Models," Paper prepared for Conference on Natural Disaster Reduction, Land Management and Sustainable Development, June 17-19, 1999, Paris, France.

Mileti, Dennis S. (1999), Disasters by Design: A Reassessment of Natural Hazards in the United States, National Academy of Sciences, Joseph Henry Press, Washington D.C.

Okazaki, Kenji (1997), "Radius - A Seismic Risk Assessment Project for IDNDR," First International Earthquakes and Megacities Workshop, Seeheim, Germany, Release II, The United Nations University, pp 319328.

Vatsa, Krishna (1999), "The Technological Challenge of Disaster Management Plan for the State of Maharashtra," Paper prepared for Regional Sharing Workshop, Asian Urban Disaster Mitigation Program Asian Disaster Preparedness Center, Bangkok, Thailand.

Yap, Kioe Sheng and Radhika Savant Mohit (1997), "Re-Inventing Local Government for Sustainable Cities in Asia: Implementing the Habitat II Agenda in Education and Training," Human Settlements in Asia: www.hsd.ait.ac.th, Bangkok, Thailand. 
(1999), "Paris Declaration," Paris Conference on Natural Disaster Prevention, Land-Use Planning and Sustainable Development, 17-19 June 1999, Paris, France.

-..- (1999), GeoHazards International Brochure, Stanford, California. 